\title{
Doctors and Nurses at the Hospitals
}

Mainly due to unpredictability in funding and demand, British paediatric hospitals began as minute institutions with a handful of beds and small outpatient departments. The senior medical officers received no emoluments, but the minimal residential staff of a matron, house surgeon, dispenser, porter, and nurses, were usually salaried entailing expenses that were unduly large for the small number of patients under care. Limited growth was therefore a built-in requirement for survival and tended to occur as soon as hospital managers realized that parents had no deep aversion to using the facilities. During its first year Great Ormond Street expanded its number of beds from ten to thirty. The General Hospital for Sick Children in Manchester expanded more slowly even though Louis Borchardt, the senior medical officer, requested an extension of hospital accommodation from the original six beds to twenty-five after the first eight months of trial as an inpatient facility. ${ }^{1}$ One year later, with still only six beds at the disposal of the medical staff, Borchardt was pointing out 'that the maintenance of each case in hospital has cost about 2 s. per day, or about $£ 3$. 2s. 11 d. for each patient [each child remaining in hospital on average for 31 to 32 days], and as with the same fixed expenses, such as rent, etc. a much larger number of children might be treated, the average cost of each case would be necessarily reduced'. ${ }^{2}$ He got his way in that the number of beds was augmented to twenty-five in the late 1850 s but no further increase was found practicable until a new hospital was opened outside the city at Pendlebury in 1872.

In their early days the paediatric hospitals functioned with a single medical resident, often called the house surgeon even though his duties were mainly of medical and clerical nature. Usually recently qualified and unmarried, he was expected to accompany the senior medical officers on their visits to the wards, ensure that their orders for diet, care and general treatment were observed, visit the inpatients at least every morning and evening, keep records of all cases and of instructions given by the honorary staff, and care for the surgical instruments. He himself could not order treatment and must inform the senior medical officer in charge of a case in the event of complications or other unforeseen circumstances. In exchange he was given board and lodging and possibly a small salary. At Great Ormond Street the house surgeon initially was expected to serve voluntarily, as did the more senior medical officers, but by 1853 difficulty in recruiting suitable candidates rendered it advisable for the hospital to offer $£ 20$ per annum, proffered not as salary but as 'expenses for rations'. ${ }^{3}$ Most of the later developed paediatric hospitals paid their house surgeons some kind of a salary. However, the East London Hospital for Children at Shadwell managed to obtain house surgeons and house physicians, well into

\footnotetext{
1 Twenty-Seventh Annual Report of the General Hospital and Dispensary for Sick Children (Manchester, 1856), p. 7. Although the General Hospital was opened in May, 1855, the Dispensary had been in existence since 1829 , so accounting for this being the twenty-seventh annual report rather than the first.

2 Twenty-Eighth Annual Report (Manchester, 1857), p. 8.

${ }^{3}$ Great Ormond Street Archives (hereafter G.O.S. Archives), Medical Committee Meeting, 5 January, 1853.
} 


\section{Doctors and Nurses at the Hospitals}

the 1890 s, without offering any emoluments at all. Nor, usually, was there any shortage of applicants for these posts with sometimes as many as eight or nine registered practitioners applying for an appointment at the East London. ${ }^{4}$ If the medical committee was satisfied with the work of the resident physician after the usual tenure of six months, he was then awarded an honorarium of 15 guineas.

Right up to the end of the century, Great Ormond Street expected candidates for its house appointments to be male physicians, qualified women not being considered until the outbreak of World War I. ${ }^{5}$ Yet hospitals for children offered the best hope of appointments for women who were obtaining medical qualifications and licensing during the last twenty years of the century. ${ }^{6}$ As early as 1869 , Elizabeth Garrett obtained the post of honorary physician at the East London Hospital for Children, in part because she most favourably impressed one of the members of the board, James Anderson, who would later become her husband. Miss Garrett had obtained a licence to practise in 1866 from the Society of Apothecaries, which had then promptly altered its regulations so that other women could not do likewise. ${ }^{7}$ Undeterred, another aspiring woman doctor, Sophia Jex-Blake, sought to persuade the University of Edinburgh to admit women medical students, which it did in 1869 , and to allow them to complete their medical education and take the qualifying examinations, which the University finally refused to do in $1872 .{ }^{8}$ Enormously frustrated but not despairing, Miss Jex-Blake returned to London where she opened the London School of Medicine for Women in 1874. One of her allies was Dr. W. B. Cheadle, then assistant physician at Great Ormond Street, but strongly opposed to her enterprise were Charles West, then serving his final year as medical officer at Great Ormond Street, and Sir William Jenner, retired as active physician but on the committee of management. In 1878 West was a principal upholder of the refusal by the Royal College of Physicians to grant its licence to practise to women (a decision that was not reversed until 1926). ${ }^{9}$ But this made little difference to the women's cause for in 1876 parliament had passed an Enabling Bill removing any statutory ban to the acceptance of women medical students. The following year the Royal Free Hospital was persuaded to become a teaching hospital for women, while the King's and Queen's College of Physicians in Dublin agreed to admit women to its examinations. The way was now clear for women to get a similar medical education to men and to take the same qualifying examinations.

\footnotetext{
${ }^{4}$ Archives of Queen Elizabeth Hospital for Children, Hackney, Medical Committee Report Book of East London Hospital for Children, 17 November, 1892, contains a report of 11 applicants for the post of house physician including one woman; ibid., 26 January, 1893, 8 applications for the post of house surgeon. The East London Hospital for Children later was renamed the Princess Elizabeth Hospital for Children and, in 1942, was amalgamated with the North Eastern Hospital for Children, Hackney, to form the Queen Elizabeth Hospital, Hackney.

5 Jules Kosky and Raymond J. Lunnon, Great Ormond Street and the Story of Medicine (London: Hospitals for Sick Children and Granta, 1991), p. 33.

6 A recent history of women's struggle to become members of the medical profession is, Catriona Blake, The Charge of the Parasols: Women's Entry to the Medical Profession (London: The Women's Press, 1990).

7 Ibid., p. 66; Jo Manton, Elizabeth Garrett Anderson (London: Adam and Charles Black, 1958), p. 57.

8 Sophia Jex-Blake, Medical Women: A Thesis and a History (Edinburgh: Oliphant, Anderson, \& Ferrier, 1886), pp. 61-166. For a briefer and more objective account, see also: 'Women in Medicine', in John Walton, Paul B. Beeson and Ronald Bodley Scott (eds), The Oxford Companion to Medicine, Vol. II (Oxford: University Press, 1986), pp. 1456-68. A recent biography is, Shirley Roberts, Sophia Jex-Blake: A Woman Pioneer in Nineteenth Century Medical Reform (London: Routledge, i993).

${ }^{9}$ Charles West, Medical Women: A Statement and an Argument (London: J. \& A. Churchill, 1878).
} 
In 1879 Annie Clark, who earlier had been one of Miss Jex-Blake's associates in the attempt to gain medical qualification at Edinburgh, applied for the position of assistant resident medical officer at the Birmingham Hospital for Children. She had obtained a doctorate in medicine at the University of Bern in 1877, and the following year gained the licence necessary for registration from the Irish College of Physicians. ${ }^{10}$ In 1878 she was appointed resident medical officer to the Women's Hospital at Birmingham, acquitting herself so well that, the following year, the election committee at the Children's Hospital (composed of medical men) chose her in preference to the male candidate, Dr. Bernstein. ${ }^{11}$ The solicitors to the charity expressed the opinion that the appointment of a lady would be illegal, as the laws of the hospital then stood. Undeterred the election committee persisted, and a somewhat fearful committee of management accepted the appointment of Dr. Clark only under protest. Sure enough, an indignant Dr. Bernstein threatened to take legal action if the decision were not reversed in his favour. ${ }^{12}$ A placatory letter from the committee of management, saying it was bound to accept the decision of the election committee, seems to have stilled opposition and the regulations were later altered so that 'in reading the laws and bylaws relating to the medical staff, it shall be understood that the masculine pronoun shall for all purposes include the feminine'. ${ }^{13}$ So well did Dr. Clark discharge her duties that not only did she receive an effusive recommendation at the end of her term of office plus an appointment as extra acting physician, but also she was replaced as assistant resident medical officer by another woman doctor, Alice Marston. ${ }^{14}$ Furthermore, the senior post of resident medical officer, also being vacated, was given to Alice Ker, another graduate of Bern. Apparently most content with the work done by the female residents, the committee of management was soon considering how to improve the living quarters 'in the event of ladies being appointed'. ${ }^{15}$ In the meantime Annie Clark continued her association with the hospital while engaging in general practice at Edgbaston, and was later appointed honorary physician to both the Women's and the Children's Hospitals in Birmingham.

Another woman, Eliza Walker, who had obtained her M.D. at Zurich, was not so successful. In 1873, she competed with 12 male applicants for the position of resident medical officer at the Bristol Hospital for Sick Children. But here the medical staff had objected to her appointment on the basis that she was unregistered-unavoidably so at the time. ${ }^{16}$ However, the hospital committee 'were unanimously of opinion that considering the special character of the Institution as a Hospital for Children and a dispensary for Women, there would be a peculiar fitness in electing a lady to the vacant office'. Apparently aware that such a decision would incur the wrath of the hospital doctors, the committee called a special meeting of the subscribers, where the principle that medical

10 'Obituary-Ann E. Clark', British Medical Journal, i (1924): 502-3; also Lancet, i (1924): 571-2.

11 Birmingham Children's Hospital Archives, Minutes of Committee of Management 1877-1885, Meeting of 19 August, 1879; Rachel Waterhouse, Children in Hospital: A Hundred Years of Child Care in Birmingham (London: Hutchinson, 1962), pp. 83-4.

12 Ibid., Meeting of 5 September, 1879.

13 Ibid., Meeting of 11 October, 1880.

14 Ibid., Meeting of 10 May, 1881.

15 Ibid., Meeting of 12 February, 1883.

16 An account of Dr. Walker's appointment and later resignation may be found in The Bristol Hospital for Sick Children, Eighth Annual Report (1874), pp. 12-13; in Blake, Charge of the Parasols, pp. 160-1; and in Charles J. G. Saunders, The Bristol Royal Hospital for Sick Children (Bristol, 1960), pp. 11-13. 


\section{Doctors and Nurses at the Hospitals}

and surgical appointments should be open to women was upheld by votes of 72 to 17 . Walker was duly elected and two of the consulting surgeons promptly resigned. A month later one of the honorary staff also saw fit to resign over a 'misunderstanding' with Dr. Walker and all the rest of the medical staff, but one, followed suit. Under these circumstances, within a few weeks, the resident medical officer felt obliged to tender her own resignation 'under terms which left them [the committee members] no alternative but to accept it.' They may have heaved a collective sigh of relief for the mass resignations had attracted much public attention apart from being totally disruptive to the workings of the hospital. Eliza Walker later married, continued to live in Bristol, and became medical officer for the Dispensary for Women and Children. ${ }^{17}$ Apart from illustrating the professional difficulties encountered by pioneering women doctors, these two incidents suggest that when the medical staff of a hospital presented a united front they could override the wishes of hospital directors. Quite often this unison was lacking, as will be seen, but gradually the hospital physicians learned the necessity of being organized amongst themselves.

While the paediatric hospitals remained small, the resident medical officer was not overburdened with ward duties and could provide other services such as helping out in the outpatient department and administering anaesthetics. With growth came expansion of medical staffing, both salaried and honorary, and more specialized duties. By the early 1890s Great Ormond Street employed a non-resident medical registrar (at an annual salary of $£ 52$ ) and a resident house physician ( $£ 60)$ for wards containing more than 60 medical beds, also a non-resident surgical registrar (£40) and assistant house surgeon ( $£ 40)$, plus a resident house surgeon (£50) for a surgical component of 42 beds. ${ }^{18}$ At the same time the Evelina used the services of a senior resident medical officer at $£ 70$ per year and a junior one at $£ 50$ per annum for 33 medical and 33 surgical beds, while the East London employed a resident medical officer at $£ 80$ per year, assisted by an unpaid house physician and house surgeon, for 46 medical beds and 46 surgical ones. None of these three institutions funded the services of a specialized anaesthetist, but the Alexandra, the Cheyne and Paddington Green did so. ${ }^{19}$ By now most paediatric hospitals had also found it necessary to provide medical assistance, usually unsalaried, to help the voluntary senior medical officers get through their ever increasing outpatient loads.

Hospital dispensaries were full of animation. Complaints were frequently made by the medical staff, parents, and even people living near the hospitals, about the hectic conditions prevailing. As early as 1859 , Charles West asked the management committee to be relieved from attending outpatients and to appoint an assistant physician in his place. ${ }^{20}$ At the same time, Mr. Athol Johnson, who was finding the surgical side of outpatients overburdensome, requested the committee of management to add to the medical staff an assistant surgeon to help out on the days when surgical patients were seen. They both got their way, the new assistant surgeon being Timothy Holmes who would later become a very influential and successful member of the London medical elite. By the 1890s, the Great Ormond Street outpatient department required the services of four extra physicians

\footnotetext{
17 Jex-Blake, Medical Women, p. 96; Blake, Charge of the Parasols, p. 221.

18 Appendix to Third Report from Select Committee on Metropolitan Hospitals, B.P.P., 1892 (321), Vol. XIII, Sess. 1.

19 Ibid.

20 G.O.S. Archives, Medical Committee Report, 23 February, 1859.
} 
and three extra surgeons apart from the often less reliable attendance of the senior hospital physicians. Incidentally, the latter cannot properly be called consultants, as they would today, for in the nineteenth century the 'consulting' status implied semi-retirement from hospital work. Physicians and surgeons so entitled no longer had regular hospital duties but, being held in respect for their previous service, quite literally acted as consultants in medical and administrative matters.

Lowliest amongst the hospital medical staff were the house surgeons and physicians. Most would become general practitioners equipped with a better than average knowledge of how to cope with children and their diseases. But during their residency they often led a lonely life isolated in their so-called 'apartments' when not on the wards. Intended to be on call day and night for any emergency, if they worked the hospital single handed they could only leave the premises for any protracted length of time with special permission. Naturally they were discouraged from fraternizing with the nurses and seem frequently to have had difficult relations with whomever directed the nursing staff, whether matron or lady superintendent. Almost as soon as Great Ormond Street had opened, the matron, Mrs. Willey, reported that the house surgeon had 'evinced considerable ill feeling towards her by speaking disrespectfully of her in different parts of the establishment, thereby tending to bring her into disrepute and prevent her carrying on her duties properly'. ${ }^{21}$ She asked the committee of management to request the medical committee to call upon the house surgeon to speak to her directly and state when she had neglected her duties and behaved in an unladylike manner, as alleged. The route may have been devious but Mrs. Wiley won handsomely since the house surgeon came to express his regrets and to retract all disrespectful comments made 'inadvertently'. The following year she was again battling with another house surgeon, but this time the medical committee declined to become involved. Jurisdiction over the nursing staff was the main source of disharmony but the medical committee had no clear idea of where lines of demarcation should be drawn between the responsibilities of the house surgeon and those of the matron. For, having given as their unanimous opinion 'that the control of the nurses, and management of the wards in all points of a purely medical nature, as for instance, the regulation of temperature, the exclusion or admission of light and air, the diet, exercise, and repose of the patients, rest with the House Surgeon as the deputy of the Medical Officers', the members of the committee then went on to state that the authority of the house surgeon and matron was co-ordinate, and that neither 'has the right to interfere with the directions issued to the nurses by the other'. ${ }^{22}$

Problems involving the allocation of responsibility and authority would abound at Great Ormond Street and other emerging paediatric hospitals in part because of the novel nature of these institutions and also because the founders required higher and more specific standards of inpatient care than was usual in other hospitals at the time. To a large extent they had no choice in this matter for, if children's hospitals were to survive, parents, donors, and the community at large must be convinced that the small patients were being extremely well cared for, far better than would be possible in their own homes or even in the comfortable homes of the more prosperous. Consequently, strict and specific rules were laid down for the conduct of nurses. Instant dismissal would follow the striking of a

21 G.O.S. Archives, Matron's Report Book, 11 March 1852.

22 G.O.S. Archives, Medical Committee Meeting, 18 May, 1853. 


\section{Doctors and Nurses at the Hospitals}

patient, and even 'not to be able to make children happy' was decreed as sufficient reason for terminating employment. ${ }^{23}$ So was falling asleep while on duty (an occupational hazard among night nurses) as one girl discovered when she was summarily dismissed after having been found asleep on night duty twice within the space of four months. ${ }^{24}$

So strongly did Charles West believe good nursing to be critical to the success of Great Ormond Street that by 1854 he had expounded his views on the subject in a booklet entitled How to Nurse Sick Children. Although intended especially as a help to the nurses at the Hospital for Sick Children, he hoped that others who had charge of the young would find the book useful, and by purchasing it also assist the hospital financially. Much of the advice was on practical matters: on signs of illness in a small child, on looking for and differentiating between skin rashes so common in childhood fevers, on the careful observation of sleep patterns, type of breathing, appetite, fluid consumption, excreta and so on. No detail was beneath his notice, for West could explain how to bath a small child, to apply leeches or a cold pack, prop up a child with difficulty in breathing and even how best to amuse small patients by reading, singing, rocking, or with stories, 'tell them of your own childhood', for 'all children love to hear what happened to grown people when they were young'. ${ }^{25}$ But before discussing practicalities, West found space to set out at some length a nurse's duties towards the doctor in charge. In summary these were as follows:

1st. Strictly to carry out his directions as to the treatment of the patient

2 nd. To observe the patient's condition; to notice the changes in it, and what she may either know or suppose to be the effects of the treatment, so as to give a short, clear, and correct account to the doctor at each visit.

Nowhere in the book was there any mention of a matron or superintendent of nurses, or ward sister, or of the nurse's obligations to such a figure. West seems to have assumed a single-minded relationship with the nurse as handmaiden to the doctor, as was then usual in private practice and in many general hospitals. But this era was coming to an end as Florence Nightingale, and other leaders of nursing reform, would insist that for the sake of unity and consistency the whole female staff should be disciplined by the matron without interference from the hospital physicians. As will be seen, West and other physicians would have difficulty in accepting a female superintendent who dealt directly with the board of management over household and nursing matters without their intervention. Before discussing the difficulties induced by change, it is worth examining earlier conditions which made reform inevitable even though disruptive.

The fledgling paediatric hospitals found it no easy task to establish practicable systems of internal hospital management and to find suitable women to act as nurses, sisters and matrons. Traditionally nurses had been girls from orphanages, workhouses, or workingclass homes, or older single or widowed women attracted by the availability (usually) of board and lodging, as well as a small salary. Some were dedicated, others less so, but most were untrained and unaccustomed to discipline. Matrons were simply women of

${ }^{23}$ T. Twistington Higgins, 'Great Ormond Street' 1852-1952 (London: Odhams Press, 1952), p. 22.

24 G.O.S. Archives, Matron's Report Book, 22 June, 1854.

25 Anon. [Charles West], How to Nurse Sick Children (London: Longman, Brown, Green, and Longmans, 1854), p. 60. 


\section{Elizabeth M. R. Lomax}

respectable background, preferably widowed, as they would then have had the experience of running a home. But, lacking special expertise and sometimes even superior knowledge or education to some of the women under their charge, many seem to have had trouble managing the nursing and household staff. The matron's authority was further undermined in that she did not report directly to the management committee but did so via either the medical committee or a ladies committee. Mounds of paper were produced since, in the early days, committees of management sought to control all activities to the level of the most minute. The hospital staff were supposed to keep records, submit weekly or biweekly reports to the management committee and ask its permission for any unusual activity whether momentous or trivial. With an efficient hospital secretary in charge there was a chance that this flood of material would be read, digested, and acted upon, but delays or even complete inaction were of common occurrence. Early in 1853 Mrs. Willey at Great Ormond Street reported that she had cut some of the children's hair without waiting for the sanction of the committee since it was urgently required. Rather sensibly, she then requested permission to have it done at any future time when needed. ${ }^{26}$ Perhaps because she was about to resign her post, Mrs. Willey showed even greater independence in March 1855 for, having suspended the cook for staying out all night without leave, she requested permission to dismiss her from the house committee (established to relieve the committee of management from day to day hospital housekeeping affairs), but fired her anyway when the house committee failed to meet to make a decision. ${ }^{27}$

At the time, the matron at Great Ormond Street was housekeeper rather than nursing or ward superintendent. Officially she interviewed and appointed the nurses, but only with the agreement of the medical committee and an 'order' from the management committee. ${ }^{28}$ Her quarterly evaluations on the competence of the nurses had to meet the approval of the medical committee before being submitted to the management committee. Indeed, the medical officers supervised most nursing activities using the matron as their mouthpiece or agent. She was in charge but without ultimate responsibility and consequent freedom of action.

Servile, untrained and ill-paid women could not provide the high standard of patient care expected by the hospital founders. Signs of trouble may be found in many of the early paediatric hospital reports. At Great Ormond Street, Mrs. Rice, who succeeded Mrs. Willey as matron, found the work overwhelming and was so frequently sick that in $\mathbf{1 8 6 0}$ she was provided with an assistant to act as superintendent of nurses. The labour was now divided with the matron as housekeeper and internal accountant, while the superintendent had control of the nursing staff, 'with the power to report directly to the committee of management'. ${ }^{29}$ Dual control proved unsatisfactory and, in 1862, Mrs. Rice was persuaded to retire, her office abolished, and all her duties turned over to an unpaid lady superintendent who would also be in control of the nursing services. Because she was voluntary and of higher social standing and education than the usual hospital matron, and also because the former system of medical supervision had proved troublesome, the

${ }^{26}$ G.O.S. Archives, Matron's Report Book, 6 January, 1853.

27 Ibid., 9 March, 1855. Mrs Willey resigned her post on 22 March, 1855

28 G.O.S. Archives, Minutes of Committee of Management, 29 April, 1852 and R. A. Clavering, 'Dr. Charles West and the Founding of the Children's Hospital in Great Ormond Street' (1956, MS in the G.O.S. Archives), p. 80.

${ }^{29}$ G.O.S. Archives, Minutes of Committee of Management, 4 December, 1860. 


\section{Doctors and Nurses at the Hospitals}

regulations formerly constraining the matron's actions were rescinded and the lady superintendent was encouraged to report directly to the committee of management.

In giving the lady superintendent such freedom of action, and independence from the hospital physicians, the governors of Great Ormond Street were in effect fulfilling the advice of Florence Nightingale, who believed that nursing reform could be effective only if a well educated efficient woman were in sole charge of the nursing and domestic establishments. But when one remembers that the Nightingale Training School did not open until 1860, and that less than ten probationers (intended to be the hospital sisters and matrons of the future) were trained there annually during the first few years, one realizes that Great Ormond Street was in the forefront of the reform movement. ${ }^{30}$ The lady superintendent, who remained unnamed in the hospital annual reports during her seven years of service, worked gratuitously as did her friends who acted as ward sisters. The management committee was pleased with the innovation, declaring in 1865 that 'the nursing department has been placed upon a more efficient and satisfactory footing than it had ever attained before'. ${ }^{31}$ As will be seen, the founder of the hospital, Charles West, did however object when upper-class female control of nursing became institutionalized at Great Ormond Street during the 1870s.

Upper-class women were the instruments of nursing reform generally. As suggested above, individual women volunteered their managerial services, in part fired by Miss Nightingale's example in the Crimea and anticipating the need that would later be filled by the various training schools for nurses. Apart from education and social standing, such women had unrivalled opportunity for first-hand knowledge of care, or lack thereof, provided in the voluntary hospitals because of the tradition for members of a 'ladies committee' to visit, inspect and report to the management committee on the state of patients and wards. The typical member was a subscriber, or the wife of a subscriber or of a medical officer. But some were young volunteers, daughters rather than wives who, like Florence Nightingale, wished to be socially active and useful. Catherine J. Wood, appointed lady superintendent of Great Ormond Street in 1878 , had been a visitor to the hospital as a young girl living nearby. ${ }^{32}$ She then took up reading to the small patients and, under the new regime in 1863, at the age of twenty-two, was appointed sister on one of the wards. Disturbed by the hospital rejection of children with chronic scrofula, she and a friend, Miss Spencer Percival, founded the Hospital for Hip-Joint Diseases in Childhood in nearby Queen Square in 1867. At the instigation of Charles West she was requested, in 1870 , to accept the position of lady superintendent at the newly opened convalescent home for Great Ormond Street, Cromwell House. She accepted and remained there until her appointment as superintendent at Great Ormond Street late in 1878. Although untrained, she became, in the words of Jules Kosky, 'the most respected and the most influential of all the lady Superintendents at Great Ormond Street', laying the foundations of modern paediatric nursing and training.

${ }^{30}$ For recent histories of the Nightingale Training School see: Brian Abel-Smith, A History of the Nursing Profession (London: Heinemann, 1960); Monica E. Baly, Florence Nightingale and the Nursing Legacy (London: Croom Helm, 1986); and F. B. Smith, Florence Nightingale: Reputation and Power (London: Croom Helm, 1982).

31 Thirteenth Annual Report of the Hospital for Sick Children (London, 1865), p. 7.

32 Jules Kosky, Mutual Friends: Charles Dickens and Great Ormond Street Children's Hospital (London: Weidenfeld and Nicolson, 1989), pp. 57-8. 
Surviving early reports by the lady visitors provide insight into the disparity between their expectations and those of the women hired as matrons and nurses. At the Liverpool Infirmary for Children, which opened a small inpatient facility in Hope Street in 1859, the lady visitors had a rotation whereby one superintended the internal management each week and the matron was obliged to apply to her for directions. The first matron, Mary Gregory, was a widow who resided at the infirmary with her two children but received no salary, ostensibly because 'the funds do not at present permit it' ${ }^{33}$ One nurse, Ellen Curry, received wages of $£ 9$ per year, and was expected to attend to the ten children then in the hospital, scour and clean their rooms and assist with the needlework. In spite of a 10s. increase in salary, Curry found the work too demanding and gave notice within three months. Her successor was hired for only $£ 8$ per annum, and also could not cope, so she was provided with an assistant, a young girl of only fifteen years. Within a couple of years the number of patients had nearly doubled, the matron was receiving an annual salary of $£ 20$, and there were now two assistants. But when the head nurse left, for 'a more lucrative situation', it proved impossible for a while to find a replacement of any permanence. Nurses came and left after a few weeks either of their own accord, or because the ladies committee (presumably with some input from Mrs. Gregory) found them unsuitable. Illness among the nursing staff was also a common occurrence; usually this involved only temporary absence from duty but, in November 1865 , one nurse died of typhus fever.

One solution to the problem of finding efficient staff was to open a training school. This would be done in many of the paediatric hospitals during the 1880 s but, when the idea was proposed by the management committee of the Children's Hospital at Liverpool in 1867, the ladies vetoed the suggestion as impracticable at Hope Street because of lack of proper accommodation. However, they urged reconsideration of the training proposal when the new, larger building on Myrtle Street (purchased in 1866) was ready for opening. In effect the members of the management and ladies committees planned an entirely fresh start there, for they informed Mrs. Gregory and her staff that their services would no longer be required after the move. This was no idle threat for, after the new hospital was opened early in 1869, when one of the former nurses applied for reappointment she was firmly rejected, the committee resolving 'that Mary Ann Liston be not engaged as nurse or any one who has been employed in the old infirmary on Hope Street'. ${ }^{44}$ Thus a ten year chapter of unfortunate relations between management and nursing staff was closed.

According to the revised regulations, adopted in 1868 , the matron was still only a housekeeper, with charge of household furniture and goods, the maintenance of cleanliness, and of provisions and diet for the patients. No reference was made as to the management of nurses except that the matron shall 'attend to the care of the Institution under the direction of the Ladies Committee, and in conformity with the regulations from time to time laid down by the General Committee'. ${ }^{35}$ However, the new matron, Mrs. Dickin, must have demanded greater authority for, by 1871 , the ladies committee admitted that 'the order and comfort of the institution cannot be maintained unless there is a responsible head', and stated, somewhat mistakenly, 'that they always understood that the

${ }^{33}$ Liverpool Infirmary for Children, Myrtle Street, Ladies Committee Book, 16 February, 1859.

34 Ibid., 10 May, 1869.

35 'Constitution and General Laws', Thirty-fifth Annual Report of the Liverpool Infirmary for Children (Liverpool, 1887), p. 14. 


\section{Doctors and Nurses at the Hospitals}

matron had the entire control of management of the female servants, and that both nurses and house servants were to obey her in all things as their responsible mistress' ${ }^{36}$ The matron was gaining greater autonomy although the official regulations did not reflect any change until the mid-1890s when a lady superintendent was appointed no longer under the direction of the ladies committee but with her own direct channels to the committee of management.

In general the appointment of a lady superintendent went hand in hand with curtailed powers for ladies committees or even their elimination. At its inception Birmingham Children's Hospital had the traditional type of ladies committee to oversee housekeeping, visit the children and advise parents on the proper care of their offspring on discharge. But when a lady superintendent was appointed in 1869 , the role of committee members was reduced to visiting the wards. Soon the committee was dissolved although about twentysix lady visitors continued to be attached to the hospital as friends for the children, and to collect money to 'provide necessary comforts for invalid outpatients' ${ }^{37}$ According to Lawley Parker, honorary secretary to the hospital, the ladies committee was dissolved because 'it was found some zealous spirits rather clashed with the House Committee and with the Lady Superintendent' ${ }^{38}$ The secretary's letter continued somewhat patronizingly: 'We have lady visitors who visit periodically and who bring any matter they think needs investigation before the House Committee. This prevents friction and as a fact they seldom move anything or make complaints. The object of appointing them is to secure their interest in the Hospital'. The lady visitors had been truly defanged but remained useful because of their skills at collecting funds for the hospital.

Lawley Parker's letter was to John Henry, secretary to the Edinburgh Children's Hospital. At this hospital the secretary was effectively the hospital superintendent, being the person to whom all complaints were addressed and who decided the issues to be brought to the attention of the board of directors. At this hospital also the ladies committee wielded considerable clout, especially when organized by an energetic secretary as happened in the late seventies with Henrietta A. Anderson in charge. She had very decided views as to how the patients, wards, and dispensary should be managed and readily informed Henry when she disapproved of the behaviour of the matron or of members of the medical staff. In 1879 Anderson spearheaded an attack on the matron, Mrs. Snowdon, complaining that the wards and kitchens were uncleanly and that when such matters were brought to the attention of Mrs. Snowdon she was rude to the lady visitors. Soon the medical staff was involved in a debate as to the efficiency of the matron, and a sizeable correspondence on the matter piled up in the secretary's office. One of Snowdon's supporter's, Dr. Livingstone, pointed out how her authority was undermined by the ladies committee. '. . . it never was imagined', he wrote to Henry, 'that the Secretary of the Ladies Committee would take it on her to override the Matron and interfere with her management of the Servants and of the household details'. ${ }^{39}$ The ladies committee was expected to work 'in conjunction with' the matron in hiring nurses but, according to

\footnotetext{
36 Liverpool Infirmary for Children, Myrtle Street, Ladies Committee Book, 13 March, 1871.

37 Waterhouse, Children in Hospital, pp. 54-6.

38 Edinburgh Medical Archives, LHB 5/22/9, Letter from Lawley Parker to John Henry, Secretary to the Edinburgh Hospital for Sick Children, 25 February, 1879.

${ }^{39}$ Edinburgh Medical Archives, LHB 5/22/12(10), letter from I. Livingstone to John Henry, 10 July, 1879.
} 


\section{Elizabeth M. R. Lomax}

Livingstone, it was not imagined 'that the Secretary [of the Ladies Committee] is to write the Matron that "I have" engaged so and so, and to tell the Matron, as she would do to her own Cook if she went away from home, to write her and tell her what is going on in the house'. This clash, which ended up in Snowdon being pressured into resignation, illustrates how difficult it could be for a working-class matron to deal with a group of ladies overseeing most of her actions and considering her as a mere servant. Having no such class imbalance and not being salaried, lady superintendents could more easily placate, and even ignore, the lady visitors.

At Great Ormond Street the lady visitors were never entitled to supervise the matron's activities as they were at Liverpool and Edinburgh. Even their advisory role was quite limited for they reported to the committee of management (whose members were supposed to visit the hospital themselves) for only three years, from 1860 to 1863 , at which point a lady superintendent replaced the matron and the lady visitors again took a back seat. But the extensive lady visitor reports written in the early sixties again demonstrate that the standards of nursing expected by these upper-class women were often not fulfilled. ${ }^{40}$ One of the most outspoken commentators was Louisa Twining, a friend of Florence Nightingale and herself a pioneer in workhouse and nursing reform. In 1857 she organized a Workhouse Visiting Society, which apart from providing services to inmates also publicized the poor conditions within the workhouses and their sick wards. ${ }^{41}$ In 1861 an Industrial Home was opened in London, under the patronage of Baroness BurdettCoutts and with Miss Twining as resident manager. ${ }^{42}$ The aim was to train workhouse girls for useful employment including nursing and, as part of this project, Miss Twining requested in 1860 that selected young women might be allowed to learn child care in the nursery at Great Ormond Street. Permission was granted and Louisa Twining's 'girls' seem to have fitted well into the training scheme for none, during the first year, complained to her of their treatment and only one was dismissed for 'disobedience' ${ }^{43}$ But Miss Twining was somewhat critical of the general nursing situation. In her words:

What strikes me more than any actual misdemeanours or neglects, are the short-comings in tone, motive and feeling, and the great want of unity and harmony between those who are engaged in this common work. I believe if any one of the nurses could 'better' herself, she would go directly; they seem to think a length of service a reason for wishing to move, and there is great jealousy between those who serve the different wards. Formerly, I used to think that united worship and meals might do something to correct this feeling, but I fear the various members are too widely separated for this to have done much good. ... Nurses who have spoken to me in confidence tell me of the weariness and monotony of their work, which I think we do not sufficiently appreciate; some variety, as well as actual teaching, religious and other, is essential to every one who really works hard in this way. ${ }^{44}$

\footnotetext{
40 Kosky, Mutual Friends, pp. 216-17, discusses the reports of the lady visitors, pointing out that the first one was by Dr. West's wife, Mary.

${ }^{41}$ Geoffrey Rivett, The Development of the London Hospital System 1823-1982 (London: King Edward's Hospital Fund for London, 1986), pp. 65-6.

42 Louisa Twining, 'The History of Workhouse Reform', in John S. Billings and Henry M. Hurd (eds), Hospitals, Dispensaries and Nursing (Baltimore: Johns Hopkins Press, 1894), pp. 602-8.

${ }_{43}$ G.O.S. Archives, Lady Visitors Book, 1 February, 1862, entry by Louisa Twining.

44 G.O.S. Archives, Lady Visitors Book, 20 November, 1860.
} 


\title{
Doctors and Nurses at the Hospitals
}

Two years later Miss Twining still found plenty to criticize. In her opinion, one 'superior' nurse should be in charge of each ward, and responsible for training the young women under her. 'I cannot think the present system of puffed equality will ever be successful with this class of nurses, among whom (in the absence of strong religious feeling and motive) jealousy will always prevail' ${ }^{45}$ In the same vein, she thought radically wrong the current arrangement of having two heads of house management, the matron and the superintendent of nurses. Instead she advocated a lady superintendent, a housekeeper, a superior nurse in each ward and the training of probationers, all of which was soon to become official policy at Great Ormond Street. Matrons were replaced by lady superintendents on the assumption that their higher social status and educational level would facilitate governance of the 'lower orders', that their usually profound dedication and religious faith would promote loyalty and, as a bonus, that family prosperity would enable many to serve the paediatric hospitals on a voluntary basis. As will be seen, the new system of governance sometimes proved a mixed blessing but, so long as working-class girls remained poorly educated and, as pointed out by Brian Abel-Smith, middle-class women did not come forward to be trained, it was probably essential for upper-class women to be nursing administrators. ${ }^{46}$

Some of the ladies obtained experience informally, as did Catherine Wood. Others trained in the growing number of general hospitals that were offering some type of schooling by the 1870s. One model was the Nightingale system established at St. Thomas's in 1860 and supported by the Nightingale Fund. Another was provided by Protestant orders that trained their sisters for nursing on the plan established at the German institution of Kaiserswerth, itself based on traditional religious training for nursing prevalent in Catholic countries. By 1864, according to the Lancet, there were twenty-six nursing sisterhoods in England, one of the most famous being St. John's House in London which had entirely managed nursing at King's College Hospital since $\cdot 1858 .{ }^{47}$ The governors of that hospital had initially handed control of nursing over to St. John's House:

\begin{abstract}
'We pay', says the [hospital] Steward, 'St. John's House $£ 1000$ a year, which includes all the female domestics in the house, twenty-six nurses, besides a number of probationers who are in training, and a staff of about half-a-dozen ladies, who superintend the nurses, and reside like them in the hospital. This plan has been in operation six years, and has worked most satisfactorily'. ${ }^{48}$
\end{abstract}

The council of St. John's House, an all male committee consisting mainly of clergymen and physicians, was in charge but, to satisfy the bye-laws of King's College Hospital, the lady superior of St. John's House also held the appointment of hospital matron. She and all her subordinates, therefore, in reality worked for two separate masters, a state of affairs that could not continue indefinitely without friction. As has been documented by Judith Moore, in 1874 a crisis over nursing erupted at King's College; this was resolved, or

45 G.O.S. Archives, Lady Visitors Report, 13 January, 1862.

46 Abel-Smith, A History of the Nursing Profession, p. 23.

47 'Hospital nursing', Lancet, ii (1864): 298-9; Rivett, Development of the London Hospital System, p. 104; Carol Helmstadter, 'Robert Bentley Todd, Saint John's House, and the Origins of the Modern Trained Nurse', Bulletin of the History of Medicine, 67 (1993): 282-319.

48 Lancet, ii (1864): 298. 
papered over, to re-emerge in 1883 in even more acute form. ${ }^{49}$ The issues were complicated but one cause of trouble was the desire of the committee of management of the hospital to have greater control of nursing and housekeeping. ${ }^{50}$ To the annoyance of the sisters, their own governing council did not support their demands but instead kept making concessions to the hospital committee, to the extent even of agreeing to the dismissal of the matron, Sister Aimee. Finally however, according to Moore, a demand in 1874 for the resignation also of a member of the council of St. John's House caused this body to make a stand. ${ }^{51}$ Arbitration was decided upon, with two legal members of the council of King's College acting as referees. They came out somewhat in favour of the nursing sisterhood by stating that the sisters and nurses were officers of St. John's House and not of the hospital. As part of the resolution, a new agreement was drawn up between the two institutions and Sister Aimee retained in office. But her demeanour continued to be too authoritative to suit the King's College board of management which again in 1883 asked for her resignation. The council of St. John's House concurred but not the thirty-five lady sisters who ceased work in protest. Sisters of St. John's House working at the Charing Cross Hospital joined the 'strike' in sympathy. This time no compromise was achieved and both King's College Hospital and the Charing Cross terminated their agreements with St. John's House. ${ }^{52}$ As has been discussed the previous chapter, the children's hospital at Nottingham also experimented with nursing sisterhoods only to find their style of management too intransigent to be tolerated for long by equally authoritarian committees of hospital management.

Although during the 1860 s religious sisterhoods were the only source of reliable, disciplined and well trained nurses, when the governors of Great Ormond Street found it necessary to reform their nursing system, they chose not to farm it out to any sisterhood, in part for fear of undue partisan religious influence, but instead to continue training their own nurses under the jurisdiction of a lady superintendent. To do so, the management was obliged to relinquish some of its former control, and the medical staff found they now had to deal with a more independent power. ${ }^{53}$ For the lady superintendent gained considerable influence mostly at the expense of the medical establishment, who were now no longer expected to interfere directly in nursing management but instead to channel complaints through a house committee (of varied constitution but including the superintendent of nurses, and one or two medical officers and members of the management committee). They accepted the changes in the hopes that better nursing would ensue and to a large extent were not disappointed according to the governors and even to the more sceptical Charles West. 'The power so confidently entrusted', he later wrote, 'was well used. . . . The tone of the nurses was raised, many things were better done than they had been done before, and the Committee could not but rejoice at the success of the expedient. ${ }^{54}$

\footnotetext{
49 Judith Moore, A Zeal for Responsibility: The Struggle for Professional Nursing in Victorian England, 1868-1883 (Athens: University of Georgia Press, 1988).

50 'St. John's House and Sisterhood, and its Relation with King's College Hospital', British Medical Journal, i (1874): 243-4.

51 Moore, A Zeal for Responsibility, p. 21.

52 Ibid., pp. 132-65.

${ }^{53}$ G.O.S. Archives, Reports of Committee of Management Meetings, 10 November, 1862 and 1 December, 1862.

${ }^{54}$ Charles West, A Letter to the Governors of the Hospital for Sick Children (London, 1877), p. 11.
} 


\section{Doctors and Nurses at the Hospitals}

Nevertheless, he expressed discontent when, in 1869, the first lady superintendent, Miss Bubb, resigned and a new one was appointed with equal freedom of action. He thought the trial period was over and her terms of office should be regulated as were those of everyone else at the hospital. West's discontent turned to anger when in 1872, as rules for a new hospital were being considered, the committee of management still made no move to regulate the office of lady superintendent. In July 1875, 'immediately after the new hospital had been opened to the inspection of the public', according to West, 'the [management] Committee sanctioned the claim of the Lady-Superintendent to appoint as Head Nurses persons previously untrained in any other Hospital, and thus practically abdicated all control over the internal management of the institution which became vested in the Lady-Superintendent, and a number of ladies of her own selection'. ${ }^{55}$ West recommended a male hospital supervisor, either house governor or medical director, to oversee the internal medical, nursing and housekeeping activities of the hospital and to ensure that the management committee regulations were carried out in spirit as well as in practice. ${ }^{56}$ In his opinion, women were intolerant of supervision and disliked being told of more efficient ways of discharging their duties, so often creating muddle in institutions devoid of male direction.

However, West found little support for his views among the governors of the hospital. Most of the discussion took place in personal correspondence but one medical member of the management committee, Warrington Haward, then assistant surgeon at Great Ormond Street, expressed what was perhaps the prevailing managerial view in an article published by the Contemporary Review in 1879. Good, efficient nurses, he explained, were extremely difficult to find. Since all the necessary qualifications were rarely to be found in any one individual, the best solution was to combine talents, to use the services of working-class women in conjunction with those of trained ladies. The former would, to paraphrase Haward, provide the brawn while the latter would provide direction and 'superior intelligence'. The most efficient system, in his experience, was therefore one in which the wards were run by trained ladies rather than by sisters (i.e. trained nurses not members of sisterhoods) belonging to the same class as the ordinary ward nurses. According to Haward:

It is a mistake to suppose that the most sympathetic and skillful for the poor are to be found among their own class. Any one who has seen much of their homes will have observed that the majority of the poor are congenitally deficient in, and only acquire after much training, those habits of cleanliness, delicacy, order, and restraint so needful in the nursing of the sick; and that long familiarity has produced a certain insensitiveness to suffering, disease, and dirt in those around them. ${ }^{57}$

West believed otherwise. In his opinion 'those who best know the poor will probably say teach, train, elevate the nurse as best you can; but still the truest sympathy, the most practised skill in nursing the poor will be found among the poor themselves' ${ }^{58}$ Miss

55 Ibid., p. 12.

56 Charles West, On Hospital Organisation, with Special Reference to the Organisation of Hospitals for Children (London: Macmillan, 1877), pp. 5-13.

57 Warrington Haward, 'Ladies and Hospital Nursing', Contemporary Review, 34 (1878-9): 490-503.

58 West, On Hospital Organisation, p. 36. 
Nightingale, according to Brian Abel-Smith, also 'had reservations about lady nurses, but she soon came to appreciate the contribution they could make'. ${ }^{59}$ But West felt so strongly that the office of lady superintendent should be regulated that, when the management committee at Great Ormond Street ignored his request for action, in 1877, he resigned as consultant physician and from all involvement with the hospital. No one of influence seems to have demurred, and his resignation became permanent. Ironically, the lady superintendent appointed, Mrs. Dickin, formerly matron at the Liverpool Infirmary for Children, survived for only a few months at Great Ormond Street and was replaced by Catherine Wood, for whom West had great esteem.

Conflict seems to have been inevitable since improvements in nursing required giving nursing supervisors greater autonomy and freedom from medical control. Also, since the new nursing leaders usually belonged to the upper-classes they could more easily influence hospital governors with whom they shared similar backgrounds, while most of the physicians remained relative outsiders from the middle classes. In some paediatric hospitals the medical officers were represented on the committees of management allowing for compromise at this level and for dissent to be kept under wraps, as happened at Great Ormond Street. But at Guy's Hospital, which had a more antiquated system of management, fierce and public controversy followed the appointment, late in 1879, of a new matron, Miss Burt, fresh from reorganising nursing at Leicester Infirmary. ${ }^{60}$ She wasted no time doing the same at Guy's without consulting the physicians, who protested loudly and publicly, in part because the new, stricter rules were so galling to the nursing staff that no less then fifty out of eighty women resigned within six months. The nurses appointed in their stead were mainly young ladies often not to the liking of the medical staff. According to Margaret Lonsdale, one of the recent nursing appointees, discord arose because their higher moral standards and education permitted them to be critical of the crude behaviour of the hospital physicians. Lonsdale published her viewpoint in Nineteenth Century, which for the next few months became the forum for debate between her and the medical profession. ${ }^{61}$ Like West, most of the physicians at Guy's were unenthusiastic about the new breed of lady nurses who so obviously lacked docility. But at Guy's the medical staff, which had no representation on the management committee, united in protest and of necessity went public, whereas the much more recently founded Hospital for Sick Children initially possessed a more representative administrative system which facilitated the introduction of a lady superintendent as early as 1863 with general medical approval.

Great Ormond Street was perhaps unusual in that the founders of the hospital, including Charles West, never seem to have dominated hospital management. The senior physicians and surgeons considered themselves to have parity and resented any form of autocracy, as may be seen in the fuss over the appointment of Dr. Marsh, discussed in a previous chapter. Commoner, perhaps, was the situation in which the hospital founders, lay or medical, retained disproportionate influence in hospital affairs. This seems to have been

\footnotetext{
59 Abel-Smith, History of the Nursing Profession, p. 23.

60 For details of the 1879-80 nursing crisis at Guy's, see: Moore, A Zeal for Responsibility; and Rivett, The Development of the London Hospital System, pp. 107-9.

${ }^{61}$ Margaret Lonsdale, 'The Present Crisis at Guy's Hospital', Nineteenth Century, 7 (1880): 677-84; 'On the Nursing Crisis at Guy's Hospital', ibid., 884-904; 'Doctors and Nurses', ibid., 1088-108.
} 


\section{Doctors and Nurses at the Hospitals}

the case at the Children's Hospital, Manchester where conflict over nursing erupted in 1879. One of the senior hospital physicians, Dr. Henry Humphreys, quarrelled with the lady superintendent over her dismissal of a ward sister. The lady superintendent complained of his interference in her domain to the house committee, which suspended Humphreys from his duties until the next meeting of the management committee, twelve days later. Later it would be argued that the house committee had been unduly influenced by Louis Borchardt who, although not a member of the committee, had held the meeting in his own office. Humiliated by his suspension, Humphreys sent in his resignation from the hospital before the committee of management could discuss the case. ${ }^{62}$ The resignation was duly accepted, indeed the board made no move to allow him to reconsider and later even admitted it was not sorry to be rid of him, 'for his want of clearness and decision in instructions given with regard to the treatment of patients became a frequent cause of anxiety and embarrassment, and repeatedly came under notice, finally convincing the Board of Governors that Dr. Humphreys was not suited for the position he held' ${ }^{63}$ Local physicians thought otherwise and thirty-three Manchester hospital medical officers signed a sympathetic memorial which Humphreys included in a letter to the British Medical Journal. This journal published the memorial in an editorial critical of the actions of the management committee, stating that 'the sympathies of the whole profession will be with Dr. Humphreys under these circumstances, as the case is one which seems to point to a scandalous abuse of administrative power' ${ }^{64}$ The Manchester Medico-Ethical Association called a special meeting to debate the issue and tended its sympathy to Humphreys for the unjust treatment he had received. ${ }^{65}$ Dr. Henry Simpson, president of the association went so far as to remark 'that he never recollected hearing of the medical-staff, nurses, and hospital-board at Pendlebury working in harmony'. ${ }^{66}$ Like West, Humphreys did not expect his resignation to be accepted without any effort at compromise and both men were seriously hurt professionally and personally by their abrupt severance from senior hospital positions. West was saddened until the end of his days by his rejection and exclusion from the hospital he had founded and nurtured. Humphreys, a far younger man at the time of his battle with the Pendlebury management, was in the uncomfortable position of having no immediate means of support. Because the hospital was situated in a rural area, the Pendlebury management committee had decided fully to remunerate its senior medical officers on condition they devoted themselves full time to the institution and did not engage in private practice. Thus, when Humphreys resigned, he lost a salary of $£ 300$ per year and had no other immediate source of income.

The Guy's hospital crisis over nursing management, and to a lesser extent that at Pendlebury, led to considerable correspondence in the medical and lay presses. The

62 A copy of Dr. Humphreys' letter of resignation, dated 26 November, 1879, may be found in the Minute Book of the Board of Governors, 1875-1881, G/HRM/AM2/3, at the Salford City Archives. This letter was included in the Minutes of the meeting of the Board of Governors of 6 December, 1879, and the report of this and subsequent meetings during December, 1879, and January and February, 1880, indicate the response of the governors.

63 Fifty-First Annual Report of the General Hospital and Dispensary (Manchester, 1880), p. 12. This report also contains a copy of an article from the British Medical Journal in defence of Humphreys and to which the governors were replying.

64 'Nurses and doctors', British Medical Journal, i (1880): 97-8.

65 Manchester Medico-Ethical Association, Dr. Humphreys and the Children's Hospital, Pendlebury (Manchester, 1880).

66 'The Pendlebury Hospital', British Medical Journal, i (1880): 372. 


\section{Elizabeth M. R. Lomax}

governors of both hospitals were accused of despotic management; at Pendlebury medical representation existed in the form of a house committee but, according to correspondents who had worked at the hospital, Louis Borchardt wielded disproportionate influence on the committee of management which consisted mainly of his friends. A former assistant physician at Pendlebury, Charles Rayne, who three years earlier had been coerced into resignation, wrote to provide evidence of such autocracy. Rayne claimed that instead of his position being permanent after the first year, as was more or less usual, he was merely reappointed for three months after which his connection with the hospital was ended. On inquiry he 'found that certain charges had been made against me by Dr. Borchardt, which had induced the Board to act in the manner stated. (The members present on this occasion were all laymen except Dr. Borchardt himself, and were chiefly his own private friends and patients)'. Much to the disgust of the board of governors, Humphreys, Rayne, Charles J. Cullingworth and Dr. J. Leech (two of the thirty-three Manchester hospital physicians and surgeons who had signed the memorial to Humphreys), wrote to the Manchester Guardian, as well as to the medical journals, thus ensuring local awareness of medical discontent with the hospital administration. ${ }^{67}$

To allay some of this discontent Borchardt, who had resumed his former position as medical superintendent, now also took over many of the responsibilities which normally belonged to the lady superintendent, Miss Linkes. She then became upset, stating in a letter of resignation, sent about two months after Humphreys', that she could not 'continue the grave responsibility when I have not the necessary power to correspond' ${ }^{68}$ In a second letter she wrote that her decision was irrevocable and that her early departure should not cause serious inconvenience since much of her 'work had already passed into other hands' ${ }^{69}$ Neither she nor the medical staff had gained any short term advantage but, once the immediate crisis was over, the regulations were somewhat relaxed. Even before Borchardt's death in 1883, the senior hospital physicians and surgeon were ex-officio members of the board of governors. As a group they finally profited from the public airing of internal problems which exposed the autocratic manner in which some governors ran their hospitals. As pointed out by Peterson with reference to the nursing crisis at Guy's, there the eventual outcome was an extension of medical staff power 'in the hospital to areas they had never influenced before'. ${ }^{70}$ At the Evelina increased medical advisory power followed the reorganization of hospital management in 1892. What was established by the 1890s was greater influence for the medical staff as a group as opposed to individual autocracy, lay or medical, in part because of confrontation but also because most of the original founders were either retired, exhausted, discredited or dead by then.

${ }^{67}$ Chas. J. Cullingworth to the Editor, Manchester Guardian (1880), 2 February, p. 6; Reply by H. M. Steinthal, senior governor of Pendlebury Hospital, ibid. (1880), 3 February, p. 8; Dr. J. Leech to the Editor, ibid. (1880), 3 February, p. 8; Reply by Edward Cross, chairman of the board of governors, ibid. (1880), 4 February, p. 7; Charles J. Cullingworth to the Editor, ibid. (1880), 6 February, p. 7; Chas. A. Rayne to the Editor, ibid. (1880), 6 February, p. 7.

68 Salford City Archives, Minute Book of the Board of Governors, 1875-1881, G/HRM/AM2,3, copy of letter of 3 February, 1880, to Mr. Cross, Chairman of the Board of Governors, in the report of the meeting of 7 February, 1880.

69 Ibid.

70 M. Jeanne Peterson, The Medical Profession in Mid-Victorian London (Berkeley: University of California Press, 1978), p. 186. 


\section{Doctors and Nurses at the Hospitals}

By this time also nursing management and discipline was firmly in the hands of lady superintendents or of matrons. If a medical officer was dissatisfied with nursing performance he could complain to the ward sister, who would either settle matters or refer them to the matron. Schools of nursing with structured programmes run by the senior nursing personnel gradually replaced informal training on the wards by physicians. These would not be completely excluded; they would, for example, give lectures to the probationers on anatomy, physiology and other relevant subjects. A couple of years after Catherine Wood became lady superintendent, and with the acquisition of adjoining premises to serve as a nurses' home, Great Ormond Street instituted a formal programme to train nurses not only for hospital work but also to attend private cases. Among the hospitals for children in London, by the 1890s the Evelina, the East London and the Victoria had also developed schools of nursing. There, as at Great Ormond Street, two types of trainee were accepted: the ordinary probationers who received a salary varying from $£ 8$ to $£ 26$ per year (depending on the hospital and number of years in training) and special or lady probationers who were unremunerated and usually paid the hospital a guinea a week for board and lodging. However, the latter benefited in the not very long run since they could become certified nurses after a shorter training period than the ordinary probationers. At the Victoria Hospital and at Great Ormond Street only they, as ladies, could become ward sisters after qualification, although usually only after two years further training in an adult hospital. As Abel-Smith has pointed out, the Nightingale School had instituted this dual type of entry into the nursing profession in 1867 and the system was copied by other training schools until the end of the century. ${ }^{71}$ Then it gradually fell into abeyance as general education for lower-class girls improved and lady probationers discovered that their own briefer training was no longer sufficient for the better hospital appointments. At this point also lady superintendents began to be replaced by professional, salaried matrons.

Nurses and trainees worked from ten to twelve hours a day. At Great Ormond Street the sisters were on duty from 9 a.m. until 10 p.m. with three hours off daily, one week end off out of three, and one month of vacation. The day nurses and probationers were on duty for fourteen hours with three hours off and three weeks of vacation, while the night nurses were on duty for twelve hours. In spite of the long hours of labour exacted, nursing reform was associated with considerable increase in expenses since all hospitals, including the children's hospitals, were obliged to increase the ratio of nurses to occupied beds to obtain the higher standard of care desired. Furthermore, the probationers now spent some of their time away from the wards attending classes, and maids had to be hired to perform menial tasks which had formerly been the lot of nurses. A larger nursing staff was also needed as the cases admitted became more urgent, more acute and their stay in hospital shortened, and also as surgical departments expanded. According to Burdett, by the end of the century it was 'becoming a general practice in the largest and best managed hospitals that there shall be one nurse to every two occupied beds' ${ }^{72}$ By 1891 , Great Ormond Street had a nursing staff of 39 , including 1 lady superintendent, 8 sisters, 11 staff nurses, 11 probationers, and 8 lady pupils, for an average daily number of occupied beds of $92 .{ }^{73}$ To

71 Abel-Smith, History of Nursing, pp. 29-32.

${ }_{73}$ Henry Burdett, Hospitals and Charities 1901 (London: Scientific Press, 1901), p. 75

${ }^{73}$ Second Report from the Select Committee ... on Metropolitan Hospitals, B.P.P. 1890-91, XIII, p. 473. 


\section{Elizabeth M. R. Lomax}

help defray expenses, 7 trained nurses were then engaged in private nursing outside the hospital. The charge for this service was 2 guineas for the first week and 1 guinea a week thereafter. The private nurse received a hospital salary of $£ 25$ per annum plus 10 to 25 per cent of fees earned. The Victoria Hospital made similar arrangements for private nursing but not the other London paediatric hospitals.

At Pendlebury the expenses of the training school, established in the late 1870 s, were somewhat reduced by requiring an advance payment of $£ 50$ from all probationers, ladies or otherwise, and not remunerating the ordinary probationers until their second year at the hospital. Girls unable to produce the substantial sum required could be admitted to the school on condition that they stayed for the two years of training without receiving payment for the second year. ${ }^{74}$ If, however, they left or were fired before completing training, they were expected to repay the hospital for time spent there at the rate of $£ 50$ per annum. (These rules were still in place at the end of the century) ${ }^{75}$ Such stringent preconditions seem, probably as intended, to have discouraged working-class girls for, in 1882, the entire nursing staff consisted of ladies working without salary except for the six trained ward sisters. ${ }^{76}$ Although Pendlebury, as mentioned above, incurred the unusual expense of renumerating its senior medical officers, this hospital managed, by encouraging cheap or unpaid labour elsewhere, to keep the average cost of salaries and wages per bed occupied at the same level as those incurred by Great Ormond Street. In 1891 the latter hospital reported the average cost of salaries per bed occupied as $£ 2415 \mathrm{~s}$. $8 \mathrm{~d}$., while for Pendlebury the figure was $£ 2413 \mathrm{~s} .4 \mathrm{~d} .{ }^{77}$ Like Great Ormond Street, Pendlebury was also in the business of providing nurses for private cases at $1 \frac{1 / 2}{2}$ guineas per week for ordinary illness and rising to 2 guineas for the care of children with fevers or undergoing surgery at home, as was still commonplace at the turn of the century and beyond. $^{78}$

The incomes hospitals derived from private nursing were small and the system was controversial since it entailed training nurses for the benefit of wealthy families at the expense of hospitals intended for the poor. It was also sometimes perceived as involving exploitation of the nurses themselves. But management committees favoured the arrangement as an ultimate source of income (once the nurse was trained, sometimes even before) and also in the expectancy that people would subscribe to an hospital providing such a valued service. For good nurses remained difficult to find in an era of constantly rising demand. Whereas originally the children's hospitals had provided home nursing service freely for the poor, now, in part because of chronic financial strain, they were abrogating this service and instead expanding the supply of trained private nurses.

By the end of the century one person, the hospital matron, had considerably gained in status. Forty years earlier she had been a mere housekeeper under the constant scrutiny of the medical staff and the ladies committee, who expected her to defer to them whilst also maintaining discipline among the nurses and hospital servants. This situation was conducive to frustration and outbursts of anger rather than sound management. Because of

\footnotetext{
74 'Appendix', Fifty-First Annual Report ... Pendlebury (Manchester, 1880), p. 64.

75 'Appendix', Sixty-Ninth Annual Report . . . Pendlebury (Manchester, 1898), p. 76.

${ }^{76}$ Fifty-Fourth Annual Report ... Pendlebury (Manchester, 1883), p. 24.

77 Henry C. Burdett, Hospital Annual . . . 1893 (London: Scientific Press, 1894), p. cxxi.

78 Sixty-Ninth Annual Report ... Pendlebury (Manchester, 1898), p. 66.
} 
the still rigid class distinctions of the time, it was probably essential for ladies, who could negotiate as social equals with members of management committees, to take over as superintendents of nursing. These women brooked no interference from members of the ladies committee and arranged, or demanded, clear lines of demarcation between their domain and that of the physicians. The latter did not always give way with good grace, but in the end also benefited from the much more efficient and reliable nursing system that evolved. Crises over nursing also indirectly served the medical staff because the ensuing debates covered by journals and newspapers gave them a forum to air their discontents with autocratic committees of management and senior consultants. Faced by unfavourable publicity, and a real or feared decline in subscriptions, hospital directors went to some length in pacifying their discontented medical officers. By 1900 the medical staff of most paediatric hospitals had some form of representation on committees of management. The appointment of women as medical officers continued to be most unusual and, as illustrated above, seemed to be successful only when the male medical staff gave their backing. Presumably the increased influence of women as nursing leaders was enough for most men to digest without including females among the ranks of hospital doctors themselves. 